\title{
Evolution of Design in Advertising (From Traditional to Digital) Embraced by Industry Professionals
}

\author{
Ihsan Hammouri, Dr.Jehad Ameri , Diran Maltijian, Mutasem AlKarablieh, Dr. Haifa'a Bani Ismail, \\ The University of Jordan
}

\begin{abstract}
$>\quad$ ABSTRACT
The Internet has changed the way people's ways of advertising tremendously. Design and related marketing tactics went from traditional to digital in the speed of light, thus online communications have matured a lot and it's no longer a minefield of annoying pop-up ads. Online advertising also called "internet advertising" became the most favorite of modern marketers in no time, and more methods and design features surface every day to help create effective advertising campaigns. Today marketers use the internet to build businesses, create brand awareness, reach prospects, close deals and increase sales.
\end{abstract}

In this paper, we will focus thoroughly on the evolution of digital advertising, digital design, modern designers, and we will evaluate the main differences between traditional design and communication tools VS. digital modern design in advertising.

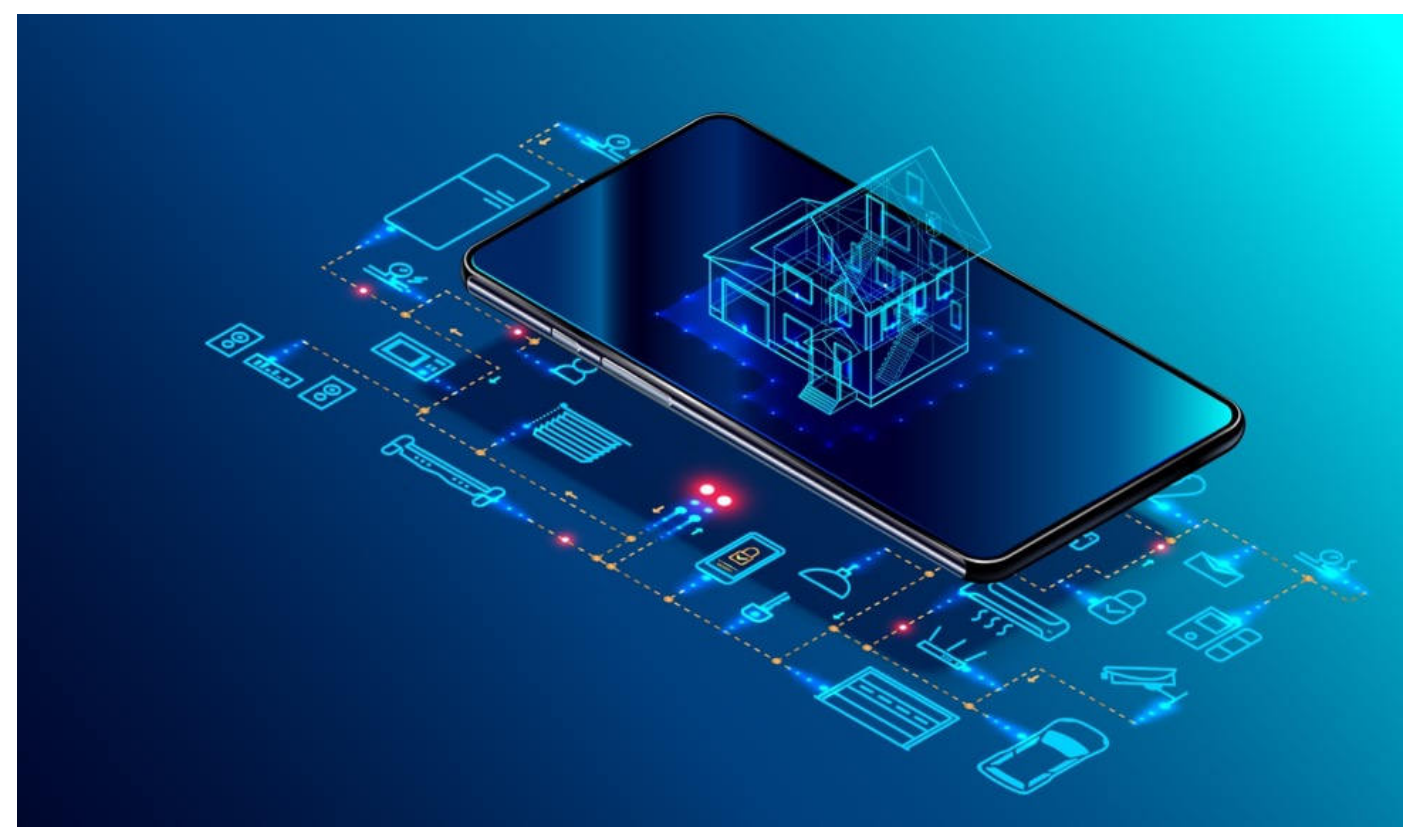

Moreover, this paper discusses the advantages of the ever-evolving digital design and communication, and how marketers use online advertising to deliver new promotional marketing messages for all kinds of products and services, to specific targeted consumers at ease, less cost and with fast and vast reach.

This document also identifies the obligatory skills for the traditional graphic designers as they move into the ever evolving digital and new media world.

Conclusions will portray the effectiveness of online advertising on the modern consumers, especially the young generation as well as the foresighted future of digital design compared to traditional tools and techniques.

DOI: $10.7176 /$ JTHS/42-06

Publication date:August $31^{\text {st }} 2019$

\section{Purpose of the Research}

> The research is designed with specific objectives which are:

- $\quad$ To define the role of design.

- $\quad$ To introduce the evolution of traditional design in advertising.

- $\quad$ To explore the differences between traditional design methods and online forms of advertising. 
To study the evolution of digital advertising, digital design, modern designers, and to also evaluate the main differences between traditional design and communication tools and, digital modern design in advertising (pros \& cons).

- $\quad$ To explore how digital marketing is entwined with graphic design.

- $\quad$ To acknowledge why marketers, prefer online/digital advertisement.

- $\quad$ To take a glimpse on the future of digital design in advertising - expectations based on the findings of the study.

\section{$>\quad$ What is Online Advertising?}

Definition: Internet advertising aims to drive consumers to certain websites or location(s), enticing them to make a purchase or a call regarding a certain product or service. Internet advertising is not just about getting in front of customers; it is more about meeting them in the right place, at the right time, with the right

message

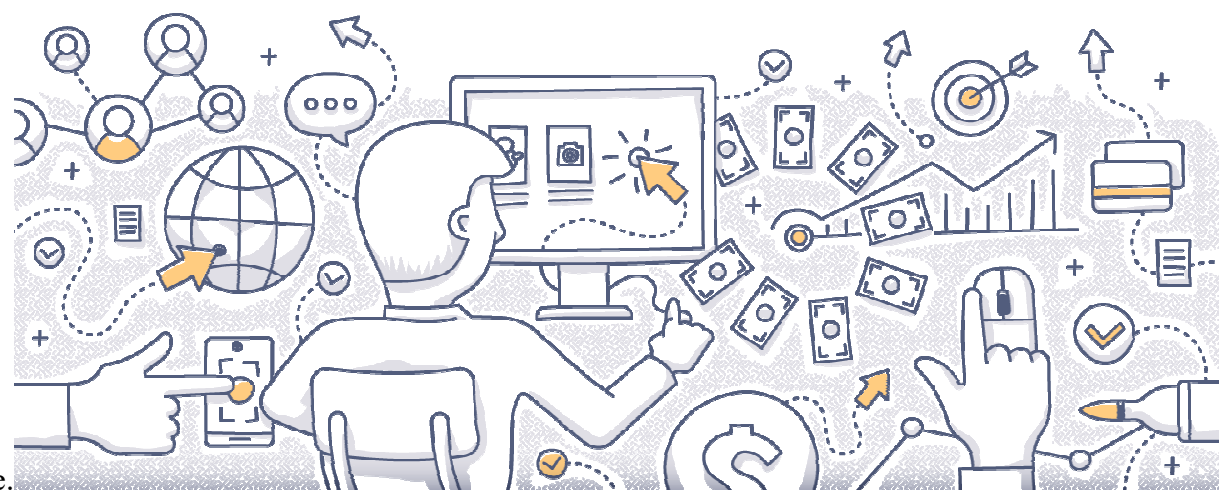

Online advertising also called "Digital advertisement" is online marketing messages, appearing in a web browser, search engine, on social media, on mobile devices, not to forget, emails. Some consumers view online advertising as an unwanted disturbance with no personal benefits, that is when they tend to turn to ad blocking, or end up ignoring the ads completely. Just like traditional advertising media, online advertising normally involves both a publisher, and an advertiser. Other potential participants include advertising agencies, which help generate and place the ad, track the results and make changes to live campaigns instead of waiting until a campaign ends in order to analyze the results and optimize their performance.

Digital marketing is similar to traditional advertising, but what differs is using digital practices. This digital world of design is constantly accelerating in terms of technology. This technology has evolved in many different ways, growing from outdoors to digital billboards such as in stadiums, while another attempt the technology has accomplished is to be simply worn on the wrist. These considerations made everyone stop and think about how to label the required new forms of design techniques and skills required for such advanced digital mediums, such as designing an interactive website compared to a static one requires a totally different way of thinking, creativity, approach and of course skills. Today the title of a digital designer is broad and encompasses different areas such as; Print, web development, videos, and multimedia.

Marketing, whether digital or traditional, is what people do to promote a business and attract customers and clients to try or buy a product or a service. Today, with the growth of the Internet; traditional marketing and Internet marketing stand at a challenging point, there has always been an ongoing battle about which method is best. The truth is, both methods can be useful, and while some marketers think there is no reason to choose one over the other, results are attracting modern marketers towards online advertising for so many reasons that will be mentioned later in this paper.

\section{A brief history of traditional advertising and the evolution of graphic design:}

There is evidence nowadays that advertising has come to existence since $3000 \mathrm{bc}$. Taking things back to the 
pre-internet days, advertising was more traditional, thus design was very primitive, aimed to persuade consumers to make certain decisions in regards to accepting, thus trusting, and then purchasing products or services.

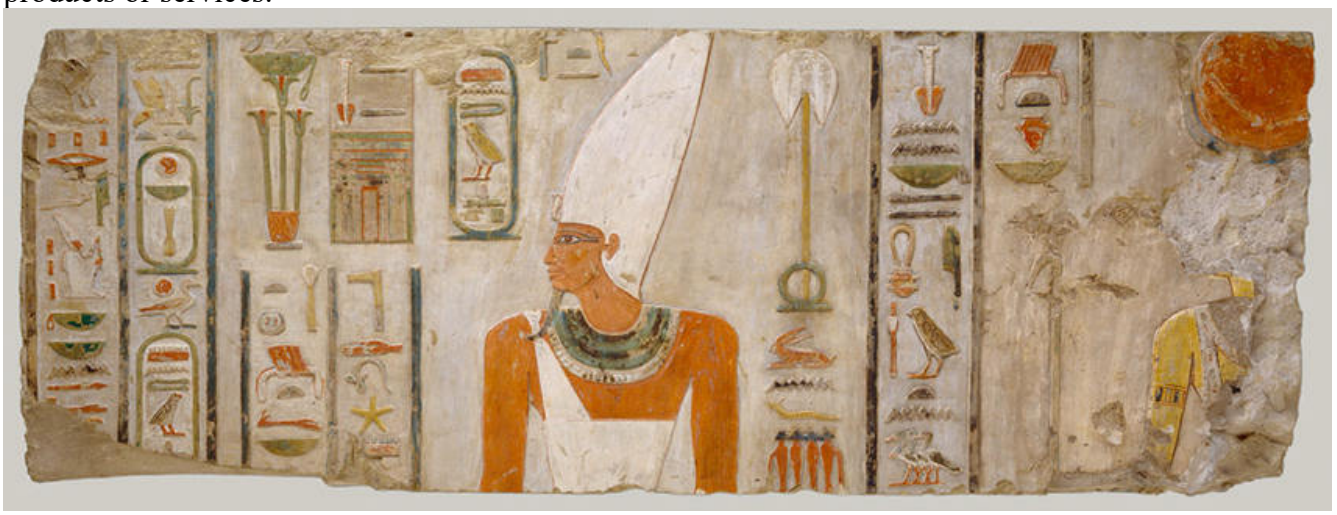

The evolution of advertising was taken from the inscriptions of ancient Egyptians as well as the Ancient Greeks and Romans. Then it emerged to the days when advertising spread through printing press that enabled ads to circulate widely in newspapers, and cheesy designed ads and creative commercials that broadcasted on ancient radios and old televisions and wooden billboards. From that day, advertisement came a long way evolving to meet the taste of the ever-changing target audiences.

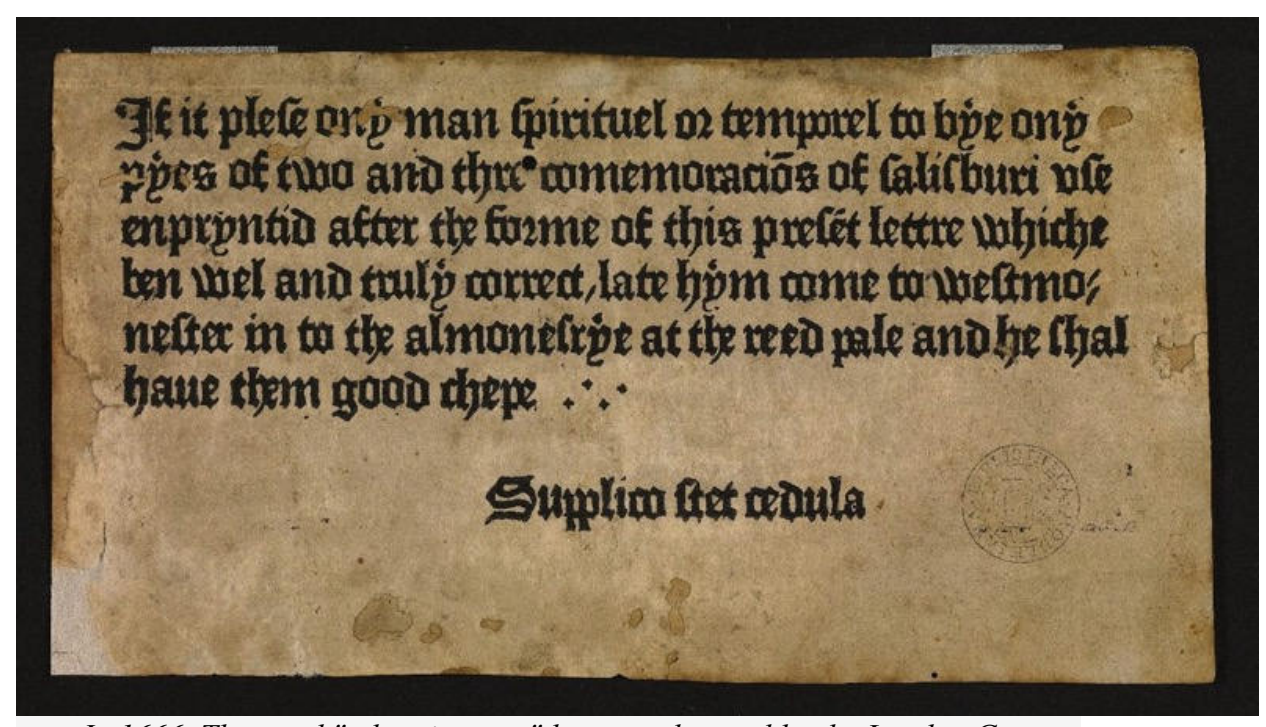

In 1666 The word "advertisement" began to be used by the London Gazette.

The digital era played major roles in changing the marketer's behavior as well as the designers' reactions and interactions in following the advancement in that field. Companies started offering personalized products and services. After that, they tailored the marketing strategies accordingly, with the aim to reach the new specified target audience for each specific product and service offering a totally new customer experience.

Twenty or even ten years ago, things looked very different. The evolution moved from paper and traditional printing to different forms of digital media. No one can deny that designing for the screen differs totally from the process of designing for printing, especially when we consider the new forms of digital media such as smart phones PADs which forced graphic designers to change their style, skills and tools to fit the interactive design world. Back in the 90s designers worked in a more hand art style and motionless illustrations, digital was more of static web development, with the advancement in technology, the role of a graphic designer evolved to design online campaigns, animated logos and 3D-6D digital artworks.

How digital advertising started: 1994 was the take-off, which started with selling Ad space on websites to 
advertisers, this space was called "banner ads" and advertisers paid upfront charges for a set time period. In 1999, advertisers were given the opportunity to bid for top search engine results on particular keywords. Payfor-placement eventually evolved into pay-per-click. This led to search results that were mainly determined by how much a company was willing to pay.

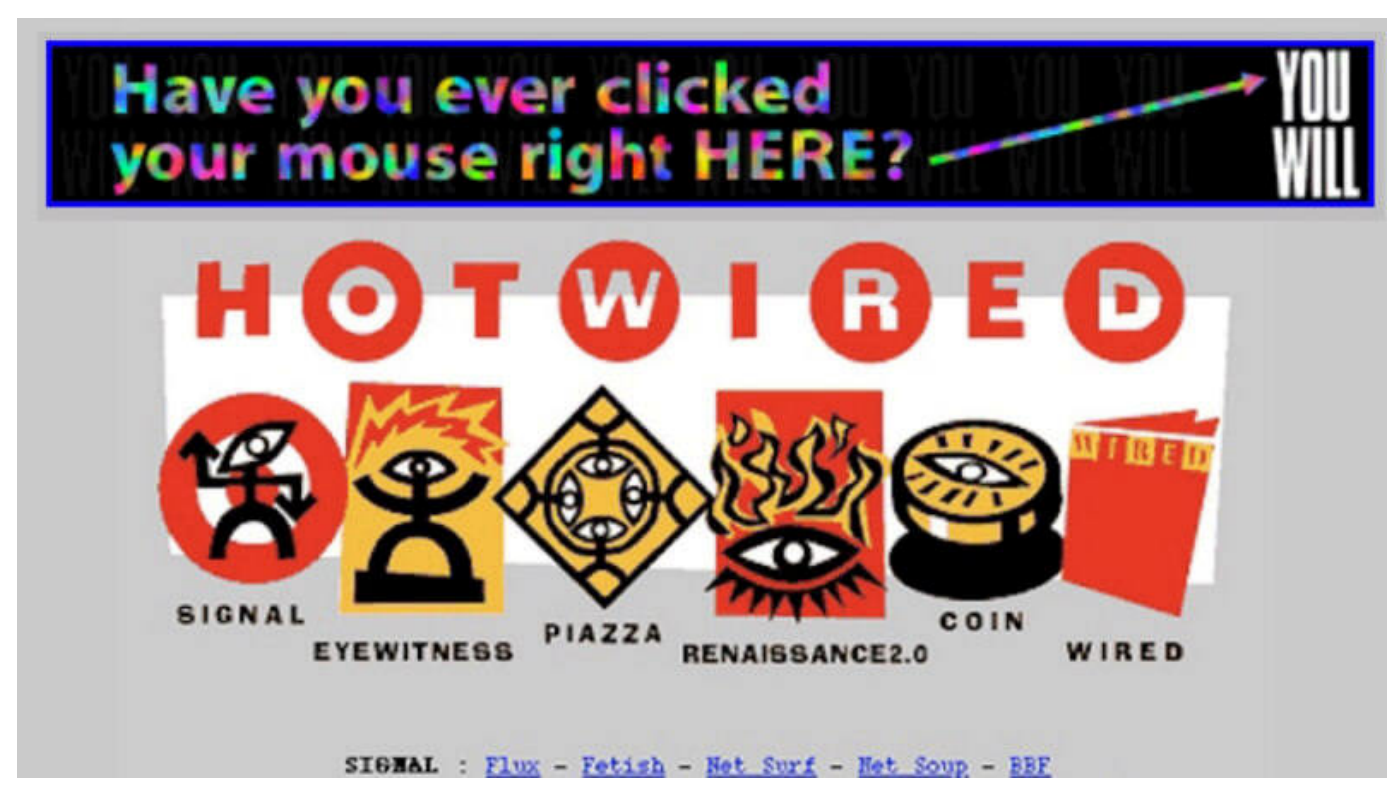

Wired magazine's HotWired.com was the first website to display banner ads.

In 2006 digital ads came to target younger and excessive internet users; that is when Facebook became a pan ad pioneer, changing the way marketers reached their desired online audiences with relevant ads. Later internet users got introduced to sponsored content "native advertising", where advertisers pay to produce articles, videos, and other types of content for

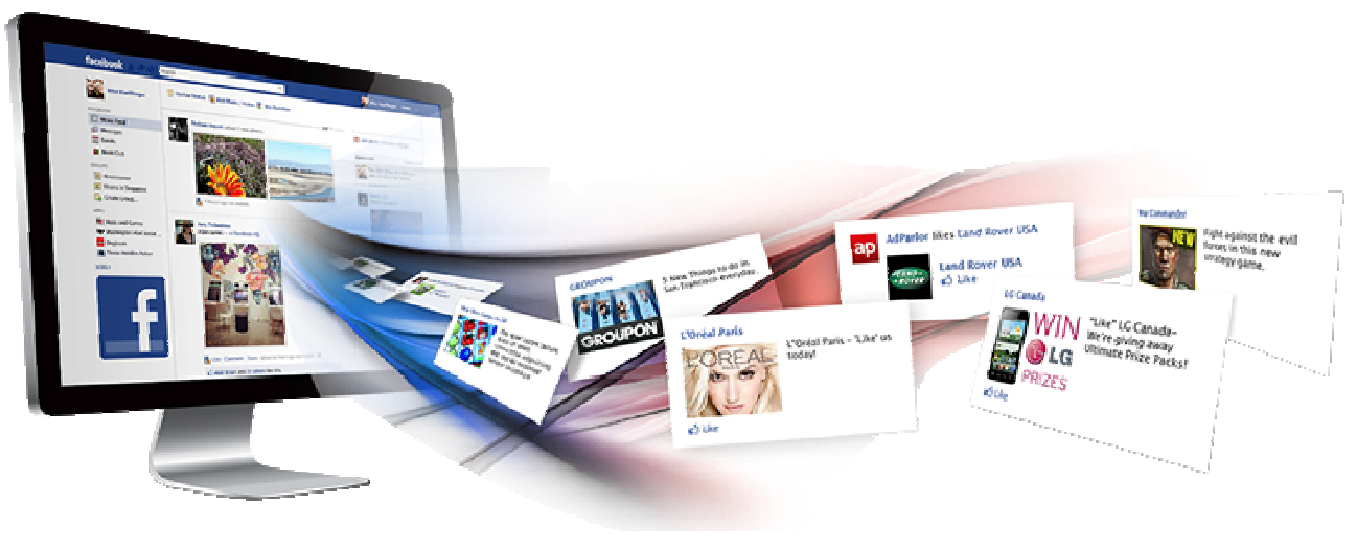

news with content that is promotional, however, the format does not look like an ad, but more of a regular piece of content on the host's website.

By the year 1979, email was introduced to the world by the US military services; it was not until the early '90s that businesses started seeing the marketing benefit in emails. In 1990, a "web browser" was invented with no clear future, it was up until 1993 when the University of Illinois released a much easier platform to use the browser. From that day on, the internet simply boomed. 
Online shopping grew in 1995, when Amazon, was introduced. The year 1994 introduced the first search engine, which was invented with features based on relevancy. Later in 2003, AdWords launched its first online campaign applying a special system that marketers could use to serve ads in response to a user's desires. In the late 2000 s, mobile apps came to existence, introduced by Apple Software Company, giving people the freedom of choice with regards to the content, products and services they desire.

\section{The Beginnings of Graphic Design:}

The term graphic design commenced ages ago with the invention of writing. Beginning from cave printings around 16,000 years ago, when people had to combine both text and pictures to describe something or in aspiration of attracting fortune back then using different techniques that developed enormously over time.

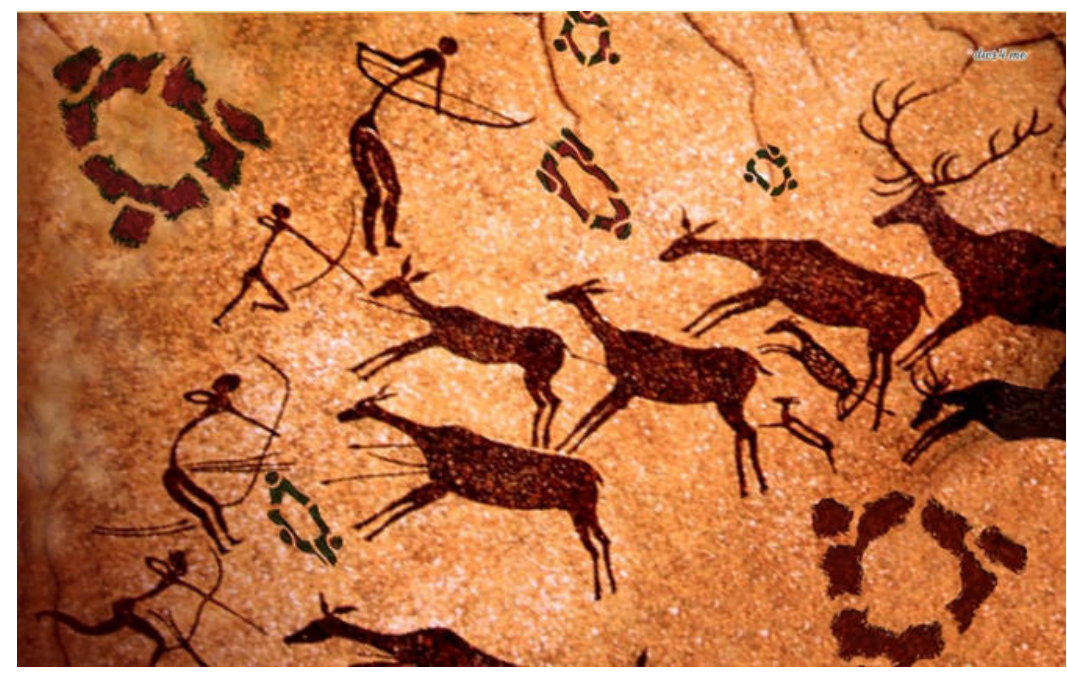

With the creation of the press in the renaissance age came the demand for intellectual growth and the burst of graphic design.

Industrial Age: The industrial revolution brought in high speed the printing presses, cameras, and then graphic design were born. By the end of Second World War the advancement of technology in advertising new businesses and industries after the war arose. Real fruitful design work came in with the introduction of the Apple Macintosh in the year 1980.

Graphic design is a very essential part of our daily lives that at most times goes unnoticed. The use of both words "graphic" and "design" goes back to the dual nature of the process. Great designs stimulate the audience intellectually and move them emotionally by using typeface and text plus exciting and inspiring imagery. The final artwork is often a combination of a collaboration of designers and animators', writers, photographers and outsourced production houses as clients invest money depending on the size of the job and the aim of the campaign.

The Field of Graphic Design expanded to fit in with the advanced technology and categories emerged.

Corporate Design: companies with investments in communications and advertising hire internal or external designers and marketing teams to fulfill their project and keep their brands consistent in the mind of the consumer.

Environmental Design: architects and advanced design trade shows rely on dimensional environment design features to present their structured products.

Motion Design: a concept that drives designer to work on adding moving visuals, sound and motion "animation" into the field for emotional or detailed conceptual projects. 


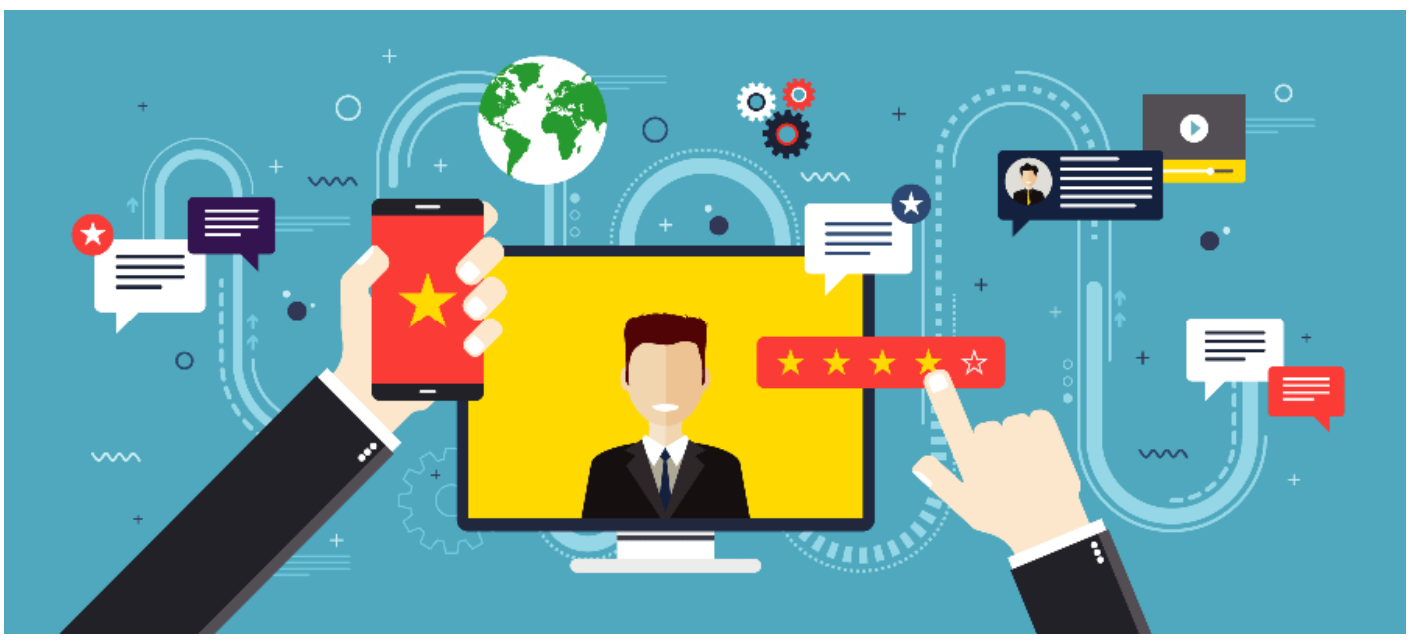

Interactive Design: is a fast changing and evolving field. Computer based concept, using software that allows the creation of interactive design broadcasted through the internet and touch screen devices. Designers need to have special skills, knowledge and experience in different programming languages to excel within this field.

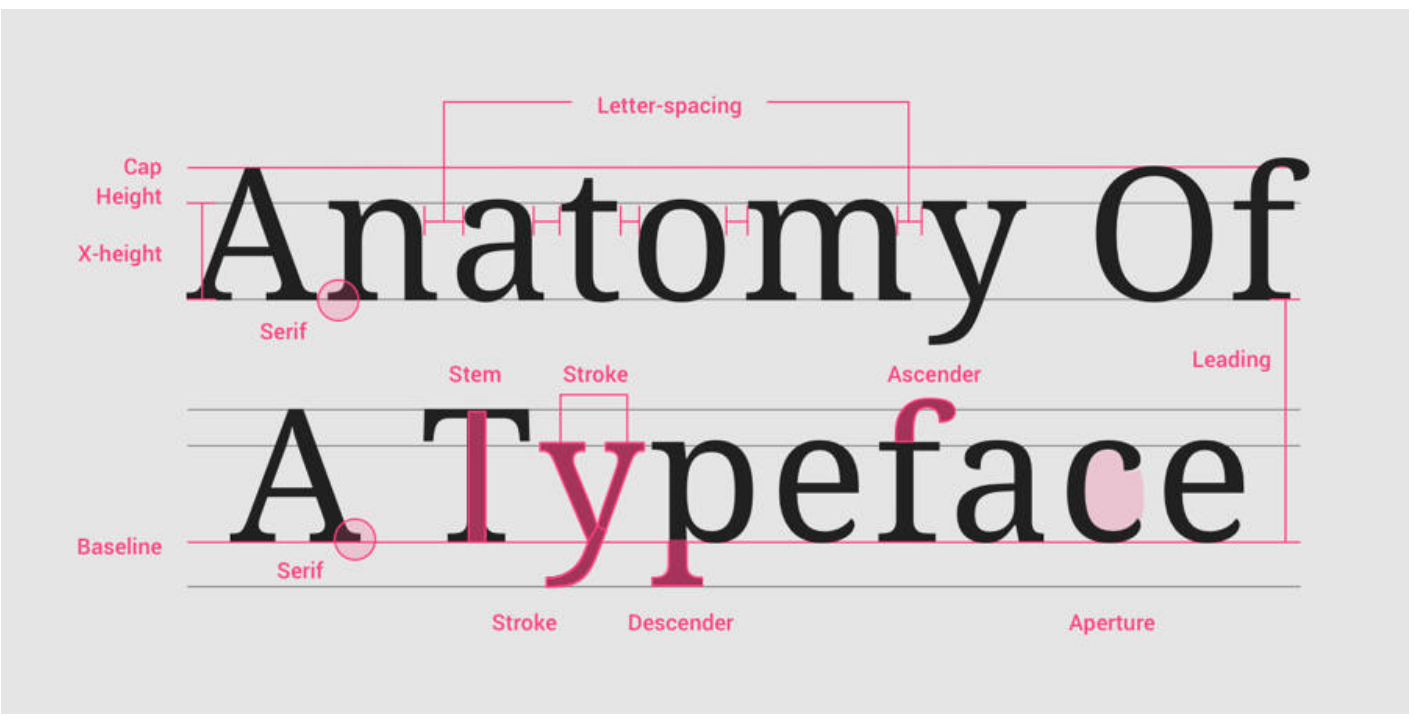

Typeface Design: A type designer creates new letterforms and fonts (variations such as bold and italics) to develop a complete typeface family. The elements include letters, numerals, ligatures (where two letters are joined), and punctuation. The designer must have a sharp sensitivity to details so that they're able to create a unified feeling within a typeface. It is important to have a strong knowledge of the history of a type and an understanding of the theoretical issues involved.

Publication Design: a category that covers periodicals in which design ads are published such as magazines and newspapers. Designs can include news, photography and typography.

Book Design: publishing books using structured design themes, inclusive of suitable layouts, content, imagery, fonts and book covers, and then preparing the book for printing or uploading on the internet.

Package

Packaging design is the connection of form, structure, materials, color, imagery, typography, and regulatory information with ancillary design elements to make a product suitable for marketing. 

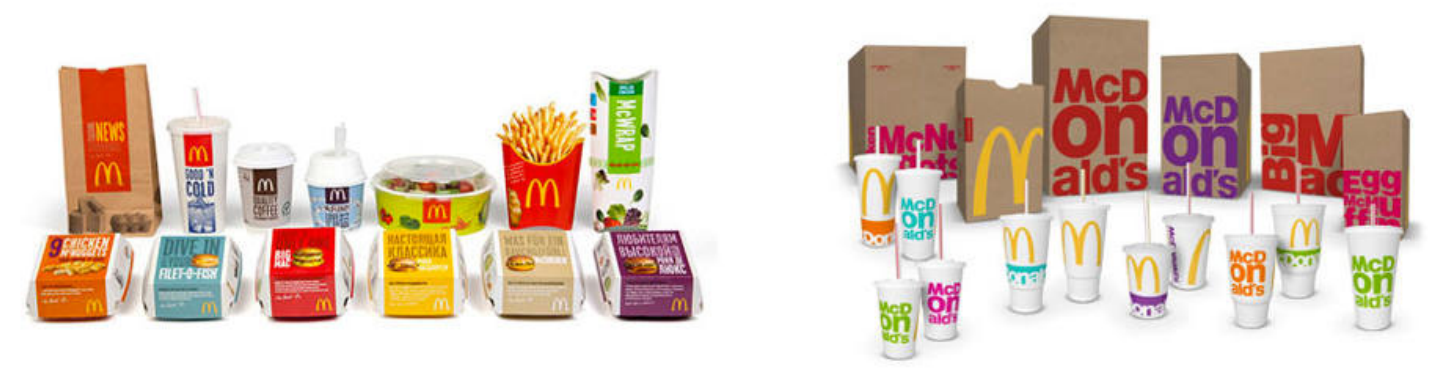

McDonald brand identity and packaging design

Brand and Identity Design: creating a company's brand identity starting with a logo to a stationery collateral material website etc...

Information Design: presenting data in an effective graphic art using special programs that add effects to contents and different materials.

Advertising Design: advertising agencies and designers with media specialists and marketing strategies come together to create well designed campaigns that are tailored for each client and specific product fusing a specific target audience through ads that are launched in different available and affordable ATL and BTL mediums.

\section{$>$ Traditional Marketing Vs. Online Advertising}

1. Traditional Marketing: A strong debate remains as to whether digital marketing is beating or actually defeating traditional marketing or not. It is undeniable that seeing people reading ads in magazines and newspapers, or billboards is still considered quite normal. Most of the time, traditional marketing is reaching its audience who are limited to the local community and is considered more like throwing information in front of people and trusting that they decide to make a move and take action.

2. The Disadvantages of Traditional Marketing: In the past, marketers found that small businesses struggled when choosing whether to spend their assigned advertising budget on Traditional Advertising or Online Advertising, or merely go for a mix of both which usually ended up in a diluted budget.

3. Digital advertising evolved with time, but can the same thing be said for traditional advertising?

Some marketers say, "One shouldn't be spending any effort, time, or money on traditional media like billboards, local newspaper ads, television, or Radio. It's just a waste of money and time”. The reasons why they believe digital marketing is considered as a better alternative to traditional advertising is:

- There is a very little interaction between the advertising tool used and the consumers. It is more of providing information to the people out there with the brand as a part of the communication on a piece of commercial with the hope that these people will engage with the brand.

- Traditional advertising is considered very costly. Producing online and below the line materials can be expensive, as no one can just launch traditional ad campaigns without an agency with an entire team of people working on the execution and media buying for a full fledge campaign, and that definitely costs a lot. Not to mention the media booking cost.

- $\quad$ Results on any traditional marketing strategy cannot be easily measured. It is rather impossible to track ROI with traditional advertising.

- Traditional advertising does not allow digging into deep analysis and getting real precise findings.

- $\quad$ Google, Facebook, Twitter, LinkedIn and mobile advertising took the highest rates in terms of reaching and engaging with the target audience. While traditional publications such as newspapers and magazines, Radio, TV channels had low rates in this regard, making them less admired tools. 


\section{$>\quad$ Digital Design Vs. Traditional Design Skills}

Traditional graphic design depends mainly on basic illustrations and design principles using simple programs for example; CorelDraw, Adobe Photoshop and InDesign to create a static Ad that can be used in printing materials such as magazines or creating simple digital logos. Print making is considered an essential part of traditional advertising, with focus on production, since it mostly revolves around print advertising in both forms; ATL (Above the Line, such as Billboards) or BTL (Below the Line, such as Brochures and stationery).

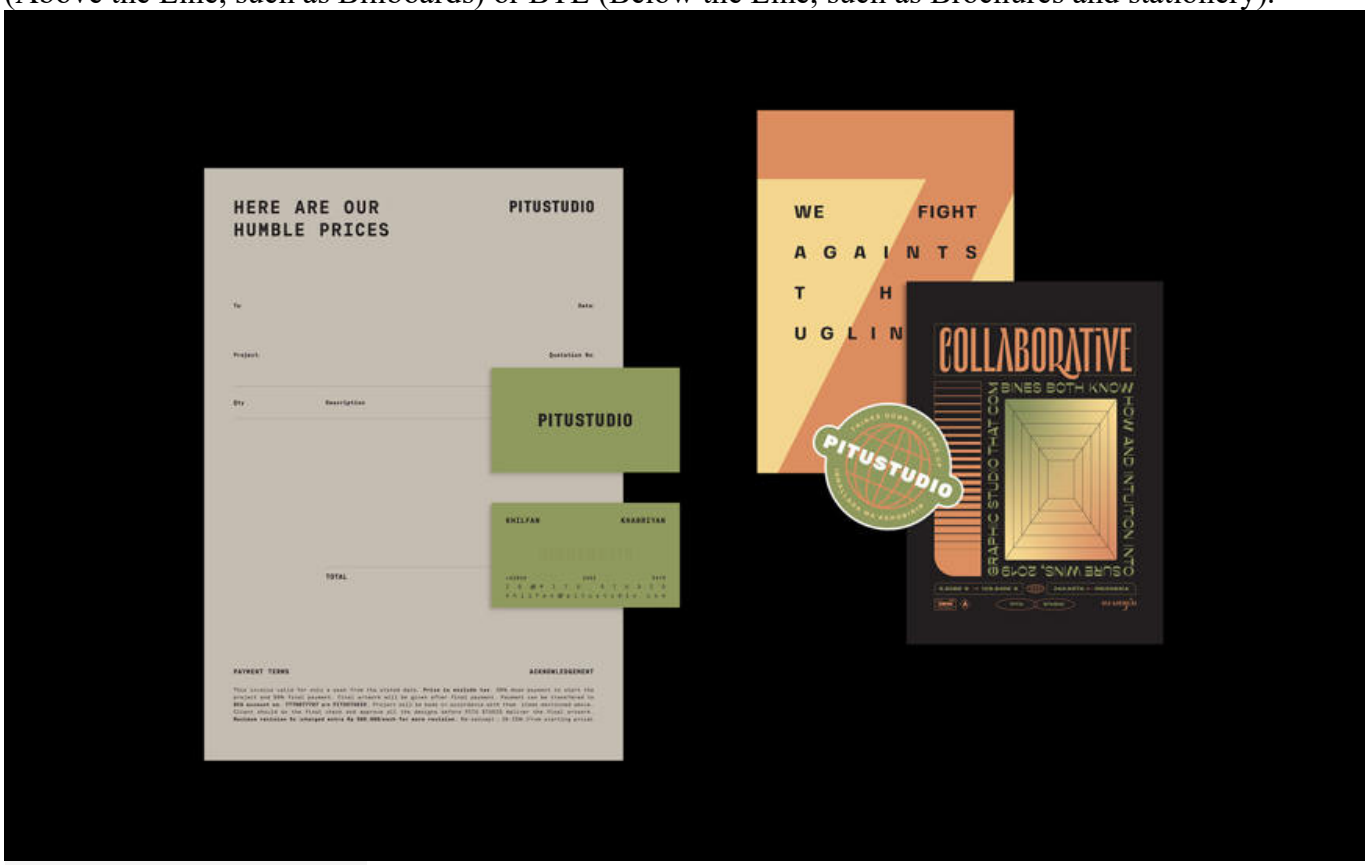

Sample of stationery design

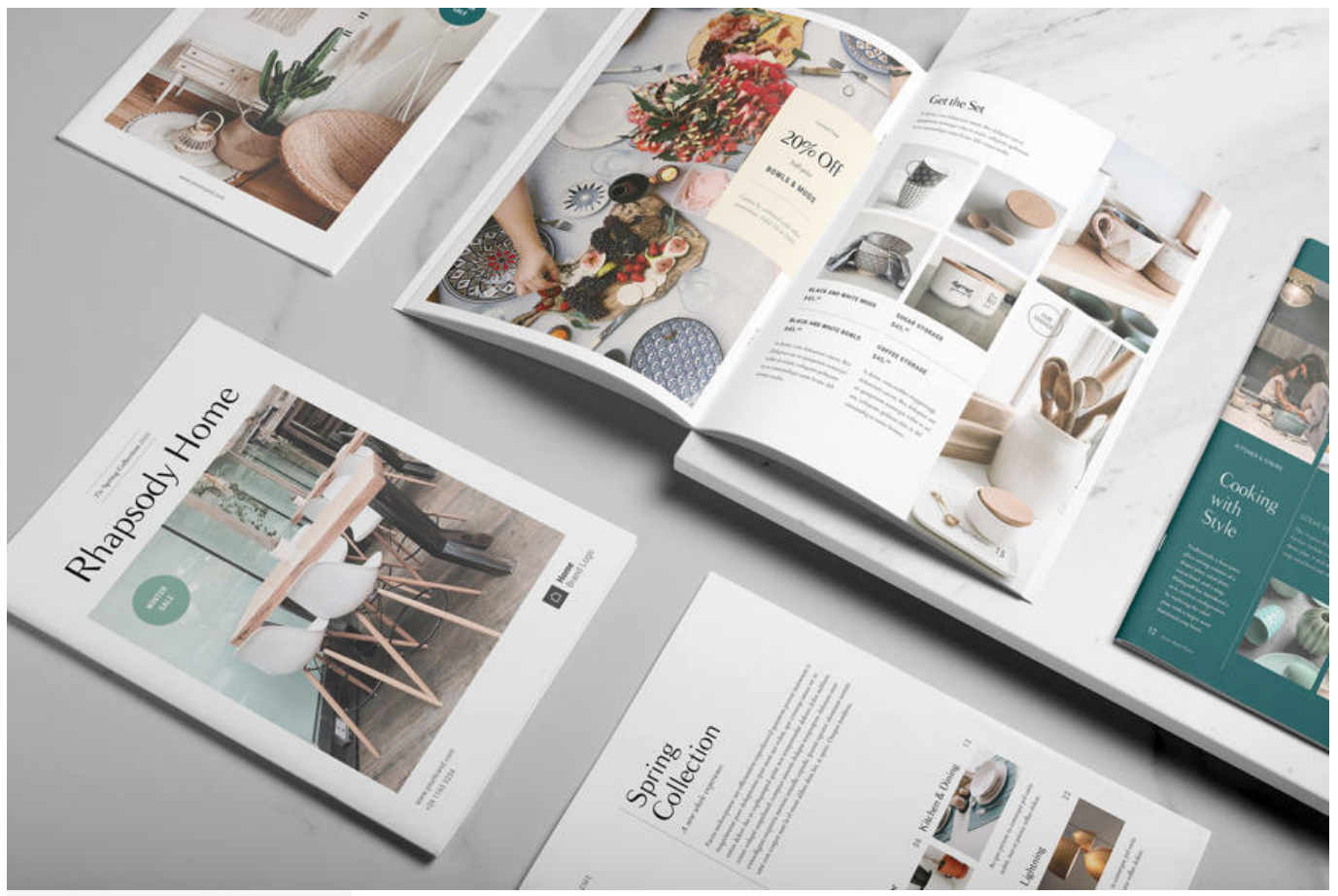

Sample of Brochure design 
On the other hand, Digital Media is more of an interactive motion of graphics such as; videos and digital audio productions. Though some disciplines used in both traditional and digital designing can overlap, still digital skills are motion based; where all digital designs are created in a digital format to appear in electronic platforms such as; interactive websites, online banners, email marketing collateral material, mobile apps etc... using technical coding and programming languages such as HTML5, JavaScript.

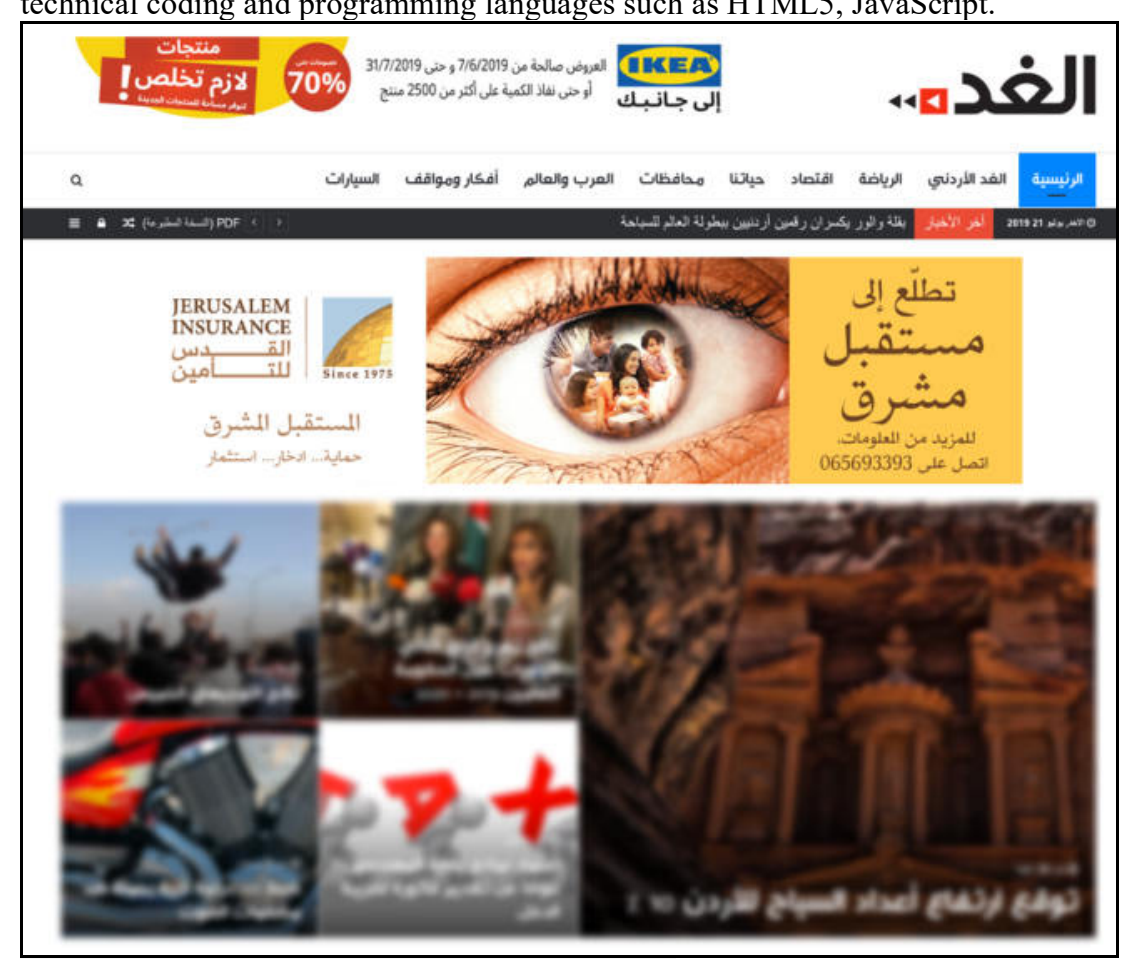

Sample of online banners on Alghad news website

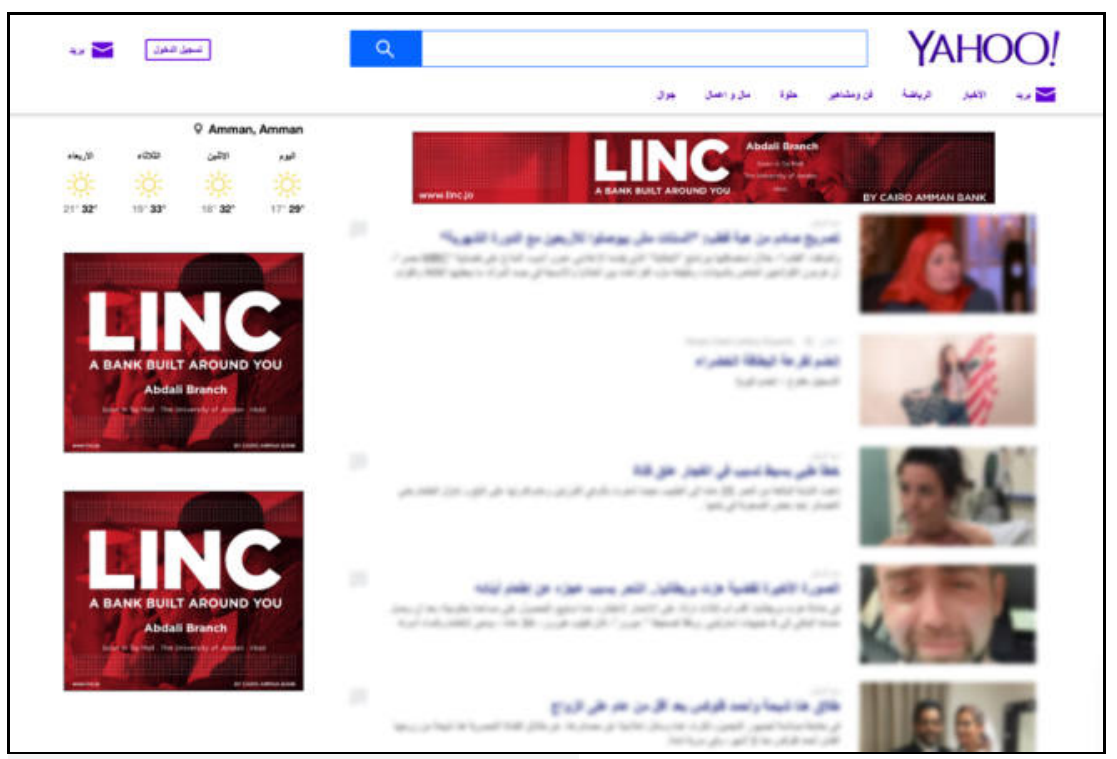

Sample of online banners on Yahoo website

\section{Pros of Online Advertising}

Findings indicate that Online Advertising has more benefits than what is clear to the mere eye, including: 
i. That traditional advertising does not give the target audience any room to choose. On the other hand, online advertising gives its target audience the power of choice, if they want to receive their content through live videos or read content or any other means.

ii. Researchers found that one of the primary benefits for online advertising is being inexpensive and cost efficient, when compared to traditional communication. Besides the fact that, delivery items can be tracked online, ensuring best customer experience.

iii. Direct relationships and high interaction are built with the target audience through online advertisement. Though the target gets only few seconds to see any message and comprehend it, still they can give feedbacks and make decisions through a simple click of a button.

iv. Social media allows brands to develop and flourish by directly communicating with specific consumers and speaking to the target market, marketers can collect data to analyze consumer behavior trends and by that get quick feedback on what's working and what the target market can provide from significant value and high lead opportunities anywhere in the world. Here any business can compete with any competitor regardless of size. Also, build brand awareness with a solid digital marketing strategy.

v. Using social media channels enables any message to be shared extremely fast. Online advertising has the ability to take any marketing message and make it viral. That is why relevant and well-structured content is extremely important.

vi. Online marketing strategies are very flexible in implementation. It can be handled by a one-person home business. Therefore, there's no need for advertising agencies and third parties' interference once a solid marketing campaign is set.

vii. Tracking software and automated tools help in tracking online campaign data's and results as well as, measure the response and give the marketing team immediate results on their campaigns in terms of success or failure, in defining traffic growth, in focusing on leads, helping them adjust the campaign when needed in order to fulfill deals with prospects.

viii. The improved Demographic Targeting based on personalized factors such as: gender, age, location, interests and hobbies. Thus, allowing campaigns to be more effective and by that increase client's response. On the other hand, in traditional advertising such as; TV, radio, magazine, newspaper targeting it can be extremely difficult.

ix. Creating and fostering long lasting relationships with customers after they purchase a product, can help lead the business or company to better sales, better customer experience and thus achieve customer loyalty. This can take place by collecting email addresses of both- the actual consumers and the prospects through an automated responding email system.

x. International reach is happening in no time, making it much easier to get to the target audience wherever and whenever.

\section{$>\quad$ Cons of Online Advertising}

There are_some major Issues with Social Media platforms which have not been totally solved yet. Though the Internet has made marketing much easier, there are still some major challenges.

It is obvious that Competition in online communication is quite BIG. The Excess amount of Information with so many accounts to follow and so many people posting new information and too many options and offerings at the same time makes it almost impossible to keep up, all that leads to confusing customers and thus distracting them from certain offers and products. This can be overwhelming, especially for small business owners. Junk material bombarding people when least expected.

Findings also indicate that Some Mistakes can cost a fortune, like for example if the marketing team targets the wrong audience, or leaves a campaign running when it was supposed to stop, it can drain out the marketing budget. One of the online disadvantages mentioned by many marketers is that it relies on highly interactive customers. Again, marketers find it a bit exhausting and Time Consuming, to continuously work on information, update it, edit, approve and publish material, respond to comments etc.... What frustrates marketers the most is when Target Customers get to Ignore Ads.; since they are in total control and have the choice to avoid clicking banner advertisements, skip Ads the minute they appear on screens, there is nothing anyone can do about it, customers will always remain in total control of which Ad they want to respond to and which not. Then there is the issue of Cyber bullying: with Children and teenagers falling as the highest victims to this crime. Another matter came to our notice is, receiving Fake information regarding certain sites and products with the aim to drive traffic thus creating mistrust and hesitation for users.

Though online advertisement is considered cheaper in relation to traditional advertisement, still Real effective Ads are somewhat Expensive. Online advertisement prices vary from inexpensive $\$ 20$-a-month placements, to thousands of dollars on popular sites, which of course can shrink a company's marketing budget, leading to insignificant return on investment. Marketers also specified an important matter that people do not notice; that is 
what they call Ad Fatigue; when ads keep running on the internet and the target audience keep seeing the same Ad repeatedly, after a while, those ads become unnoticeable and a complete waste of money.

Hacking and Privacy remains a major problem when considering online marketing.

Broadcasting Problems: Delays in websites or live videos loading time lowers the viewership of the online Ads, and by that, companies lose the opportunity to sell their products and services and may also lose potential sales.

Last point marketers concentrate on is staying consistent across all your marketing platforms in order to have a fully successful campaign and brand image. Being inconsistent in reflecting brand image and identity across different forums, blogs, social media etc. can destroy a perfect campaign, distort the Image of the brand, and defiantly waste marketing budgets.

\section{Web design is an essential tool in any effective Digital Marketing Strategy}

There are reasons why marketers spend lots of time and money on web designs as well as brand development. Modern influencers and marketers agree that web Design is an essential element to any successful digital marketing campaign/strategy. A combination of both; the right Web Design and other Digital Marketing strategy and tools, will achieve the best results in promoting any brand, product or service and thus boosting sales with the best attractive design that is well structured for the target audience and by that will attract traffic to the page. Because bringing together the correct tools and techniques next to the perfect design will not only interest and attract the target customers, but will also get them engaged, as well as it will affect how customers response to the site and even increases bounce rates.

\section{$>\quad$ The impact of Web-Design on customer experience}

Studies show that special graphic design features are extremely important as they fascinate peoples' minds. Whereas, Visuals and the overall look and feel of the web design, or any other digital medium, reflects a company's character and personality to its target customers. Looking at a full design from different perspective goes beyond fascinating people's minds but, to captivating their emotions and evoking customer's immediate response pushing them to take action. Design helps customers realize how or what product/service would suit their daily lives and why they should buy a product or use a service.

A popular website puts forth, "Creativity helps to think more efficiently, and Graphic Designers make this successful. With graphic design, an organization can take the chance of transmitting the idea to a potential customer without much struggle..."

Companies and their marketing teams work really hard to elevate their position when compared to their competitors. Today, creative graphic designers invent miracles. When included in any marketing campaign, with its simplified creative design basics, it is considered a pervasive art in the modern digital marketing world. Nowadays, graphic design evolved and became one of the most essential influence affecting the success of any modest or professional digital marketing campaign.

\section{$>\quad$ Digital marketing entwined with graphic design}

Marketers understand that no business can grow by being well promoted unless they use impressive graphics joint with strong messages in order to develop the business and attract potential clients, distracting them away from the competition. Today, the merge between digital marketing and graphic design is considered not just a plus rather than a must. A digital marketer needs magnificent related imagery or videos to support the content of any digital campaign they are handling/running, so is the case for a designer, he cannot create an impressive campaign using striking coherent imagery and videos, without understanding how these images or videos will be applied in the marketing campaign. Digital Marketing has become dependent mainly on visuals. It basically relies on specific elements that cannot be underestimated, such as the experience with image creation, including color creation and matching it with the image and the brand essence, typography and ruling graphics, as well as layout design, and the functionality of imagery chosen with the message of the campaign and target audience. 
Traditional vs. digital design visual elements - Similarities and Differences

1. Visuals: Graphics used in Graphic design that require high resolution in order to be clearer when printing, keeping the final effects into consideration while developing the design. On the other hand, digital designs can go lower on size and pixels with special effects that can be applied to give further dimensional results.

2. Method: Graphic design is more static when considering design presentation, with a one-way communication method and depending on third party interference for final printing on paper, cloth or other tangible material. While digital designs are more dynamic and lively using different kinds of screens, with an easy corrective manner and a two-way interactive user operation.

3. Colors: Color coding differ in relation to graphic design compared to digital Media illustrations, as graphic designs depend more on printing which means stronger shiny colors, following CMYK color mode. While animated digital designs don't need strong colors, on the contrary screens need to be easy on the eye without causing visual fatigue.

4. Typography: Fonts used in graphic design tend to give freedom of choice to the most effective in implementation and visual effects when choosing any specific traditional medium. As for digital designs the choice is more limited due the features of the HTML or operating system. Today this limitation is narrowing down gradually with the enhancement of the updated programs.

5. Reach: Graphic design as traditional design media spreads through traditional and mediums such as; mail delivery, posters, flyers etc... reaching a small target audience with lots of effort and high expenses. Whereas a digital advertisement using digital media is stronger in terms of design, cost, distribution and effectiveness in reaching a bigger target with different target audiences at one shot.

Design in the world of digital communication today

The label "digital" is more of a graphic style that emerged in the 90 s as a result of the innovative changes in computer technology. Staying up to date with the latest trends in the digital world became a vital aspect for any digital marketer. It's obvious how change in digital marketing are growing at a fast rate and that the industry became one of the most interesting and challenging; especially with the wild change in customer behavior and technology. Here are some futuristic predictions:

Signs prove that the future will witness the 4D and even 6D in design, especially when giving a tour around a website with a more comforting rest for the eyeballs. Very soon, it is expected that the response of the consumer will be taken into consideration and thus his emotions will be reflected on the creation of the sites. That will mostly adjust on the viewer's personality and mood. As for rebranding, it is expected to be hard or almost impossible. With the speed of online trade people will remember the strongest and most consistent and forget the rest; this is why changes are considered dangerous in regards to logos and branding any company's image. Experts advice is for users to get used to the existing brands as we know them today. Stock photography is another issue in the future of design and digital world. Some years down the road photographers will have no more scenes to take in human life, even in nature as anyone will have access to a very affordable worldwide library to choose from.

Keeping in mind that computers are not a tool but more of stimulators of tools, giving room for designers to modernize their skills in order to keep up with the latest trends in digital design and of course spend more money on updating the hardware as well as the software. In the past, production was part of the designer's role prior to converting to digital technology, but today computers and digital platforms became flexible tools for both design and production. Nowadays in a digital world so many "design graphic trends" are immersing while others are fading away or evolving such as: The "Ruined" effect, "Color Channels" Effects, Double exposure/Duotone, Creative Typography, Chaotic Typography, Negative Space Designs, 3D or even 4Ddesigns and much more.

$>\quad$ Digital Marketing Study - Industry Professional Responses

In another study they asked industry professionals where they see digital marketing heading next. That when a variety of responses evolved:

Johnathan Maharaj expresses his opinion that 'The one thing that has and will stay absolutely still is the need to be able to think creatively'

Anna Jones, CMO, Guzman y Gomez explained his beliefs that marketing will move out of its traditional shape to focus more on the full customer experience. Consumers will be in continuous need of interacting with their favorite brand at any time anywhere in the world, so the experience must be useful, relevant and tailored for the 
target to engage with. That will be hard work for the Marketers and brand owners, but the rewards will be tremendous.

Martin Ashplant, Digital Director, Metro said that there will be a return to the focus on growing a smaller but more engaged audience. He added that, pursuing mass audiences does not always raise profits and can often put a company in danger of being perceived as a clone. He also said that publishers would become more concerned with how users are consuming their products rather than how many users are consuming their products.

Some other results came from another study by (According to recent data from HubSpot Research) assured that $91 \%$ people find online ads today to be very much annoying at times. Results show that digital advertising will definitely grow in the near future, offering consumers and target audience a smooth exciting experience that do not disturb or disturb them.

Another important piece of data is that ad specialists realize how the future of online advertising depends on touching the emotions of the consumer and creating a responsive experience with the target in order to drive them to make decisions.

\section{According to BuzzSumo, these emotions move people to click:}

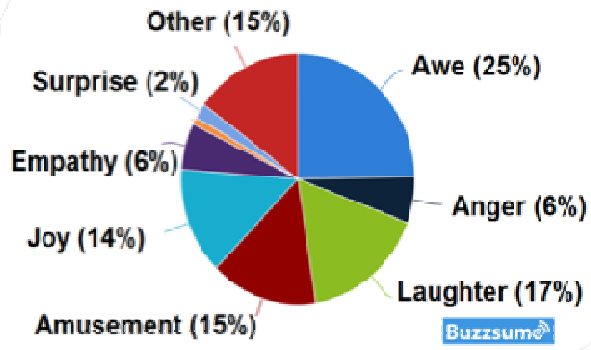

Futuristic Vision: Predictions from Forbes - How Online Marketing is changing

Technological advancement made designers work in a faster pace and in a much easier and smoother atmosphere, so some things have changed but some other things have not. Today, there are generations that grew up not knowing what it was like to exist in a world without internet and digital design. The future of graphic design is clearly going to be elevated to new heights by being fused with greater improved reality and eventually 3D printing... So where do we go from here?

I. Traditional Ads are expected to simply "DIE". People have been saying it forever, but once the internet occupies everything in the world, traditional ads will definitely die. Unless it becomes digitized in some way, such as digital billboards for example, it will either fade or change completely.

II. Companies will no longer hire in-house designers. They will depend on freelancers which will bring in huge advantages for both the employee and the company. This will save up on space rentals, overheads, equipment and running cost for companies. As for freelancers they can work from the convenience of their own place as long as they have up-to-date tools and equipment, digital skills, and internet connection. No more constraints of space and time and money.

III. Confidentiality and Privacy will be major concerns in the digital world. Brands that will offer comfort, privacy, honesty, and discrete, as rare commodities they will be the most admired and differentiated in comparison with the competing brands.

IV. Move one step closer to virtual reality. A significant change in the future is the way apps will be used in the rise of virtual reality as a standard technology.

V. New social interfaces will be introduced. Digital profiles will become more individualized, and each person will have the freedom to produce content and exchange that content with others in a much easier, faster and interactive manner, similar to the creation of reality contact lenses or glasses. 
VI. Direct communication will shrink, yet they will be highly appreciated and welcomed. Yes, the future is heading towards a digital platform, but this disappearance of personal encounters will leave consumers starving for more personal exchanges, and the brands who will offer this kind of experience, even in a digital world, will definitely lead.

VII. Voice user interfaces will become the norm. In the future the world will continue moving away from clicks towards VUIs (Voice User Interfaces) the domain of less screen's experiences, more of; Siri/Apple, Alexa/Amazon all this technology will become a new replacement of traditional graphical user interfaces.

VIII. Designers roles will change: With less job titles and emerging tools, designers will play larger roles. Finally, when there are no job titles, when all of the tools have changed, that is when designers will play larger roles in creative thinking and personalized communication. Those who will be more professional in their field of work will solve bigger problems for clients, thus creating new customer experience and brand loyalty.

\section{$>\quad$ CONCLUSION}

It is true that traditional marketing techniques are ending as many marketers declare, they say "business owners and companies will go digital". With the above discussion \& facts revealed, we can see proof that online/web advertisement or digital marketing is considered nowadays a more effective medium for reaching local or global audiences being a key factor of purchase decisions for so many consumers \& it definitely pushes brands to get on Top-Of-The-Mind and lead the competition. Still, the main concern with digital advertisement is the annoyance it creates at times, stealing away the privacy of people, producing boredom when an Ad is telecasted more than it should, and the fear of becoming a victim to online advertising fraud and abuse, not to mention the alienation in terms of personal encounters, and fast innovation for graphic designers to follow up with, and learn skills, perform using latest technology available.

Evidence shows that with the rise of online media and the drop of traditional media, people will find it easier to go online and abandon all other forms of media. This somehow makes sense to advertisers as they make major decisions in moving their advertising dollars to the web. Today, the entire world; people of all ages, people of different backgrounds and different income levels are choosing to go online, this brings online marketing to the forefront, making it the first marketing choice for advertisers as it helps in increasing the number of clients and of course higher reach, and ultimately growing profits. As for Graphic design, it changes the meaning of digital marketing being the most persuasive advertising tool in the future of the digital world. Graphic design will be more of a miracle affecting the success of any digital campaign.

Hopes are that social media will be more personalized and less noisy and easy to adapt to. For people to follow and not feel left out in a changing digital world, as it becomes an even stronger trend. All these findings support the fact that benefits of social media are greater than its downfalls... This is why online marketing is no longer considered to be an option, but it has become and will be an important part of the new lifestyle as well as the business world.

What does the future hold for design in a fast-changing digital world? As digital design and network information get to be more popular and accepted by more people, it is expected in the future to improve the consumers overall experience.

Design is becoming more and more of a strategic business discipline, and in today's fast pace digital world, creative designers need to become proficient in the latest software and design principles and advanced technique skills when communicating visual ideas. They will also need to pick up skills in advanced animation programs and techniques, not to mention their need to learn how to work with speed and efficiency to become more detail oriented in producing work under real high pressure of today's customer demands and meticulous briefs. This could happen by 2030 where most design jobs will be executed by automated robots. Moreover, as technology morphs, and new roles like a UX designer or a visual designer open the way as technology morphs, and contemporary roles like visual designer open the way to roles like AI and UX designers, only those designers with set multiple skills will survive as they will be better equipped to take on new responsibilities yet still remain flexible in team setting environment.

"Social media is the ultimate equalizer. It gives a voice and a platform to anyone willing to engage." Amy Jo Martin 


\section{References:}

Geer, D. (2018). Advertising in the digital age: why online-first is the future. [online] The Next Web. Available at: https://thenextweb.com/contributors/2018/02/25/advertising-digital-age-online-first-future/ [Accessed 5 Sep. 2018].

1. 15 Engaging Types of Online Advertising for Businesses to Increase Traffic. Raychale, (2018). [Blog] Lyfe Marketing.

Available at: http://www.lyfemarketing.com [Accessed 27 Aug. 2018].

2. Digital Marketing vs. Digital Advertising: The Difference between Digital Marketing and Digital Advertising. (2016). [Blog] Learning Catalyst.

Available at: http://learningcatalyst.in/ [Accessed 2 Sep. 2018].

3. Debono, J. (2012). Five of the Biggest and Still the Best Online Advertising Methods. [online]

Available at: http://www.business2community.com [Accessed 28 Aug. 2018].

4. Beal, V. (n.d.). Digital Advertising. [online] Webopedia.com.

Available at: https://www.webopedia.com/TERM/D/digital_advertising.html [Accessed 1 Sep. 2018].

5. Abramovich, G. (2018). 15 Mind-Blowing Stats about the Future of Advertising. In: CMO.com. Senior \& Strategic Editor.

6. Kemp, S. (2018). Digital in 2018: World's internet users pass the 4 billion mark. [Blog] We are Social. Available at: http://www.wearesocial.com [Accessed 26 Aug. 2018].

7. Marketing Charts. (2015). Assessing the State of Digital Marketing. [online]

Available at: https://www.marketingcharts.com/industries/technology-50380 [Accessed 29 Aug. 2018].

8. Makwana, K. (2015). Traditional Marketing versus Digital Marketing. [online]

Zajournalist.blogspot.com.

Available at: http://zajournalist.blogspot.com/2015/02/traditional-marketing-versus-digital.html [Accessed 25 Aug. 2018].

Sudo, L. (2016). Digital vs. traditional advertising - an advertising showdown. [Blog] Communicatto.

Available at: https://www.communicatto.com/blog/digital-vs-traditional-advertising/ [Accessed 3 Sep. 2018].

9. Template Toaster - James Cunnings (2018). Web Design as an Effective Digital Marketing Strategy.

[ONLINE] Available at: https://blog.templatetoaster.com/web-design-digital-marketing-strategy/. [Accessed 24

August 2018].

10. NetWave Interactive. (n.d.). Digital Advertising | Print Advertising | Outdoor Advertising. [online]

Available at: http://netwaveinteractive.com/marketing-services/advertising/ [Accessed 1 Sep. 2018].

11. NetWave Creative Marketing Agency (2018). Digital Advertising vs. Traditional Advertising: How

They Evolved \& How They Go Together. [Blog] Advertising \& Content Marketing. Available at:

http://netwaveinteractive.com/digital-vs-traditional/ [Accessed 24 Aug. 2018].

12. Emma, L. (2018). The Advantages \& Disadvantages of Advertising on the Internet. In: Chron. p.

https://smallbusiness.chron.com/advantages-disadvantages-advertising-internet-4029.html.

13. TINT - by Jose Angelo Gallegos (2018). The History and Evolution of Advertising. [ONLINE]

Available at: https://www.tintup.com/blog/history-evolution-advertising-marketing/. [Accessed 5 September 2018].

14. Tewari, S. (2017). Top 10 Advantages of Internet Marketing - Advantages of Online Marketing. [Blog] Digital Vidya, Internet Marketing.

Available at: https://www.digitalvidya.com/blog/advantages-of-internet-marketing/ [Accessed 2 Sep. 2018].

15. Wordstream.com. (n.d.). Online Advertising: Learn About Advertising Online. [online]

Available at: https://www.wordstream.com/online-advertising [Accessed 29 Aug. 2018].

16. Entrepreneur Middle East (2018). Online Advertising. [ONLINE]

Available at: https://www.entrepreneur.com/encyclopedia/online-advertising. [Accessed 31 August 2018].

17. E-Marketing Institute (2018). The Importance of Social Media in Marketing. [ONLINE]

Available at: https://www.emarketinginstitute.org/free-ebooks/social-media-marketing-for-beginners/chapter-25conclusion-importance-social-media-marketing/. [Accessed 30 August 2018].

18. Study.com (2018). What is Online Advertising? - Definition, Types \& Examples. [ONLINE]

Available at: https://study.com/academy/lesson/what-is-online-advertising-definition-types-examples.html.

[Accessed 27 August 2018].

19. Hub Spot - by Karla Cook (2016). What is Online Advertising? - Definition, Types \& Examples.

[ONLINE] Available at: https://study.com/academy/lesson/what-is-online-advertising-definition-types-

examples.html. [Accessed 4 September 2018].

20. Life Wire - by Daniel Nations (2016). What Is Social Media? [ONLINE]

Available at: https://www.lifewire.com/what-is-social-media-explaining-the-big-trend-3486616. [Accessed 5

September 2018]. 
21. Investopedia. (n.d.) . Social Media. [ONLINE]

Available at: https://www.investopedia.com/terms/s/social-media.as. [Accessed 26 August 2018].

22. Simplilearn - Maryanne Gaitho (2018). What Is the Real Impact of Social Media?. [ONLINE]

Available at: https:/www.simplilearn.com/real-impact-social-media-article. [Accessed 28 August 2018].

23. InforGraphic Design Team (2018). Designing Ideal Digital Marketing. [ONLINE]

Available at: https://www.infographicdesignteam.com/blog/. [Accessed 3 September 2018].

24. aBlog - by Laura Gillespie (2017). Advertising through the ages: before the internet. [ONLINE]

Available at: https://www.alamy.com/blog/advertising-ages-internet. [Accessed 1 September 2018].

25. Mindy LilyQuist (2018). Traditional vs. Internet Marketing: Which One is Best? Understanding the Pros and Cons of Traditional and Internet Marketing. [ONLINE]

Available at: https://www.thebalancesmb.com/types-of-marketing-traditional-and-internet-1794593. [Accessed 2 September 2018].

26. Digital Marketing Strategies (2018). Digital Marketing versus Traditional Marketing. [ONLINE]

Available at: http://digital-marketing-strategy.weebly.com/digital-marketing.html. [Accessed 25 August 2018].

27. Mridu Sinha. 2016. Online Marketing vs. Print Advertising: Which is best media to achieve max..

[ONLINE] Available at: https://www.linkedin.com/pulse/online-marketing-vs-print-advertising-which-best-maxmridu-sinha- $/$. [Accessed 30 August 2018].

28. Taylor \& Francis Online - by Louisa Ha Ph.D. (2012). Online Advertising Research in Advertising Journals: A Review. [ONLINE]

Available at: https://www.tandfonline.com/doi/abs/10.1080/10641734.2008.10505236. [Accessed 4 September 2018].

29. Shana Haynie (2015). Digital Marketing vs Graphic Design - When Industries Collide. [ONLINE] Available at: https://vulpineinteractive.agency/digital-marketing-and-graphic-design-collide/. [Accessed 4 September 2018].

30. What is Graphic Design vs. digital media design?. (2015). [Blog] Sanford-Brown Blogs. Available at: http://www.sanfordbrown.edu/Student-Life/blog/March-2015/Graphic-Design-vs-Digital-Media-Design [Accessed 10 Oct. 2018].

31. Graphic Design vs Digital Design. (2016). [Blog] AIT Creative Technology educators. Available at: https://www.ait.edu.au/blog/graphic-design-vs-digital-design [Accessed 2 Oct. 2018].

32. Garcia, K. (2018). From graphic design to the digital age. [Blog] Fresh Tilled Soil. Available at: https://www.freshtilledsoil.com/from-graphic-design-to-the-digital-age/ [Accessed 20 Sep. 2018].

33. Informatics and Creative Multimedia (ICICM). (2013). In: 2013 International Conference. Mahmoud Abu Shawali Applied Science Private University.

34. Darmody, J. (2018). How has technology changed the career of a graphic designer?. [Online] Silicon Republic. Available at: https://www.siliconrepublic.com/people/graphic-designer-jonathan-leahy-maharaj-fuzion [Accessed 23 Oct. 2018].

35. Graphic Design History. (2018). Digital. [Online] Available at:

https://visualartsdepartment.wordpress.com/digital/ [Accessed 12 Oct. 2018].

36. Norcross, N. (2017). How Graphic Design Is Evolving. [Online] Forbes. Available at:

https://www.forbes.com/sites/forbesagencycouncil/2017/10/09/how-graphic-design-is-evolving/\#2719232b1ff3

[Accessed 28 Sep. 2018]. 